\title{
Post-construction evaluation of traffic forecast accuracy
}

\author{
Pavithra Parthasarathi *, David Levinson \\ Department of Civil Engineering, University of Minnesota, Minneapolis, USA
}

\section{A R T I C L E I N F O}

Keywords:

Transportation demand forecasting

Project evaluation

Forecast accuracy

Model evaluation

\begin{abstract}
A B S T R A C T
This research evaluates the accuracy of demand forecasts using a sample of recently-completed projects in Minnesota and identifies the factors influencing the inaccuracy in forecasts. Based on recent research on forecast accuracy, the inaccuracy of traffic forecasts is estimated as the difference between forecast traffic and actual traffic, standardized by the actual traffic. The analysis indicates a general trend of underestimation in roadway traffic forecasts with factors such as roadway type, functional classification and direction playing an influencing role. Roadways with higher volumes and higher functional classifications such as freeways are underestimated compared to lower volume roadways and lower functional classifications. The comparison of demographic forecasts shows a trend of overestimation while the comparison of travel behavior characteristics indicates a lack of incorporation of fundamental shifts and societal changes.
\end{abstract}

(c) 2010 Elsevier Ltd. All rights reserved.

\section{Introduction}

Travel demand forecasts are routinely used to design transportation infrastructure. For example, demand forecasts help determine roadway capacities or the length of station platforms in transit projects and so on. The evaluation of proposed transportation projects and their subsequent performance depends on the demand forecasts made in support of these projects, ahead of project implementation. The high cost of transportation projects, limited availability of resources, irreversibility of such decisions and associated inefficiencies make it essential to focus on the (in)accuracy of transportation forecasts.

While research efforts have focused on improving technical aspects of a typical four-step transportation planning model, few studies have evaluated model accuracy by comparing forecasts to actual traffic counts (Horowitz and Emslie, 1978; Mackinder and Evans, 1981). The Minnesota Department of Transportation (MnDOT) conducted a forecast accuracy study in the 1980s to measure the accuracy of the long range traffic forecasts produced between 1961 and 1964 for the Twin Cities Seven County Metropolitan area with a horizon year of 1980 (Page et al., 1981). The objective of the study was to measure the historical accuracy of the long range traffic forecasts produced in the 1960s when computer based modeling was still in its infancy.

\footnotetext{
* Corresponding author. Tel.: +1 6514820625.

E-mail addresses: pavi0006@umn.edu (P. Parthasarathi), dlevinson@umn.edu (D. Levinson).
}

The accuracy was estimated by comparing the forecasts produced in the 1960s by the computer based forecasting model against the actual 1978 traffic counts collected. A total of 330 reports were used providing a database of 391 major roadway links of which 273 roadway links were used for direct comparison of traffic forecast to the traffic counts. This direct comparison indicated a mean absolute percentage error of $19.52 \%$ with a percentage error range of $-59.9 \%$ to $+56.9 \%$. Further the analysis indicated that traffic forecasts on $61.5 \%$ of the links were underestimated compared to the actual traffic counts and the forecasts were more accurate for higher volume roadways.

There has been a recent revival of interest in evaluating the accuracy of project forecasts following project implementation, in part, due to recent books on large-scale infrastructure projects (Altshuler and Luberoff, 2003; Flyvbjerg et al., 2003). While both these studies looked at the role of various technical analyses in project development, the role of travel demand forecasting and the accuracy/inaccuracy of forecasts made in support of these projects have been of particular importance.

This research follows on the current research interest using data from the Minnesota Department of Transportation (Mn/DOT) to estimate (in)accuracies in roadway traffic forecasts and also analyze the reasons for the presence of inaccuracies. The rest of the paper is organized as follows. The next section provides a brief review of relevant literature followed by a description of the data used for analysis. The illustrative, quantitative and qualitative analyses conducted in this study to estimate inaccuracies are then described. This is followed by a discussion on identifying reasons for the presence of inaccuracies in traffic forecasts. The paper concludes with key findings from the study and provides recommendations to improve forecasts. 


\section{Research synthesis}

\subsection{Error/uncertainty in model forecasts}

Researchers have traditionally focused their efforts on identifying and developing methods to incorporate the errors/uncertainties present in the traditional four-step transportation planning model (Gilbert and Jessop, 1977; Ashley, 1980; Pell and Meyburg, 1985). Clarke et al. (1981) expanded previous work on error and uncertainty in forecasting and scenario analyses to focus on the error and uncertainty in travel surveys by comparing the differences in reported trip behavior of the residents in Oxfordshire town of Banbury in Great Britain from two different survey instruments, namely the conventional trip diary and an activity diary. The results confirmed their hypothesis with the activity diary providing significantly higher reported trip rates and travel times compared to the conventional trip diary.

Talvitie et al. (1982) conducted an analysis of the total prediction error in a disaggregate mode choice model for work trips by using measures of average absolute error and root mean square error using data from the following sources: pre-BART data set collected in 1972, post-BART data collected in 1975, Baltimore, Maryland data set collected in 1977 and the Twin Cities data set collected in 1970 . The results indicated that the total prediction error in the mode choice models were rather large and varied between 25 and 65\% of the predicted value with the Twin Cities data set showing the highest prediction error.

Few researchers have also proposed theoretical approaches to identify and incorporate uncertainty in urban transportation planning (Mahmassani, 1984; Niles and Nelson, 2001). Zhao and Kockelman (2002) investigated the stability of a traditional fourstep travel demand model by simulating the propagation of uncertainty in a 25 -zone network. The results indicated that the average uncertainty increases in the first three steps of the forecasting process - trip generation, trip distribution and mode choice while the final traffic assignment step decreases average uncertainty. The results also indicate that uncertainty is compounded over the four stages of the forecasting process. The final flow uncertainties produced at the end of the forecasting process are higher than the input uncertainty.

Hugosson (2005) developed a procedure to utilize the 'Bootstrap' method to estimate the sampling related uncertainty in a travel forecasting system. The Swedish National Travel Demand Forecasting System, also called SAMPERS, was used to estimate the standard errors and confidence intervals of the total demand in origin-destination matrices and on link flows. The results from the study indicated that the uncertainties are $\pm 10-15 \%$ in total demand on OD matrices and at a 5\% risk level in demand on links and train flows. The uncertainty in the value of time was slightly higher at $\pm 16 \%$ for cars and $\pm 23 \%$ for other modes. Similar to Hugosson's work, de Jong et al. (2007) developed a method of quantifying uncertainty in traffic forecasts in The Netherlands using LMS, the Dutch national model system with a specific focus on the A16 motorway extension in the Rotterdam area.

\subsection{Other factors influencing model forecasts}

Some researchers have attempted to improve model forecasts by focusing on the impact of variations in the modeling process on performance. Daly and Ortuzar (1990) addressed the problem of the appropriate level of aggregation in a travel demand model by focusing on the mode choice and trip distribution procedures in the travel demand model. The authors designed an experiment to assess the importance of data disaggregation and mode-destination choice integration using data from recent studies in Santiago,
Chile. The results indicated that data aggregation affected the quality of the mode choice routine in the forecasting process.

Johnston and Ceerla (1996) looked at the impact of feedback in the trip distribution step on model forecasts using the Sacramento Regional Travel Demand Model. The authors noted that the lack of feedback in the trip distribution procedure results in forecasts that are biased in favor of the build alternatives (capacity enhancements) due to underprojections of the trip lengths induced by the added capacity, which in turn resulted in biased cost and emissions estimates.

Chang et al. (2002) conducted a simulation study with eleven transportation analysis zone structures and two types of network structure to test the effect of spatial data aggregation on travel demand model performance using the Idaho Statewide travel demand model. The study found that models with smaller zonal structure generated shorter trip lengths, higher interzonal trips percentage, better estimated traffic volumes $(\mathrm{V})$ to observed ground count ratios (A) and lower percentage root mean square error between $\mathrm{V}$ and $\mathrm{A}$. The variation in network detail showed a negligible effect on the trip length or proportion of interzonal trips but impacted the percentage root mean square error between $\mathrm{V}$ and $\mathrm{A}$.

Rodier (2004) applied the model validation procedure to the Sacramento, California regional travel demand model to test the model accuracy, model prediction capabilities and the model representation of induced travel. The study concluded that the model captured about half of the estimated induced travel trips, modestly overestimated vehicle miles traveled (VMT), vehicle hours traveled (VHT) by $5.7 \%, 4.2 \%$, respectively, and significantly overestimated vehicle hours of delay (VHD) by $17.1 \%$.

Another explanation for the underestimation seen in forecasts, specifically road forecasts, can be attributed to the non-incorporation of induced traffic into the model forecasting procedure. The theory of induced demand states that increases in highway capacity induces additional growth in traffic resulting in increased levels of vehicle traffic. From an economic perspective, the travel demand increases as the cost of travel decreases due to capacity improvements resulting in an elasticity of demand associated with travel (Noland and Lem, 2000; Noland, 2001).

Goodwin (1996) provided an average value for elasticity of traffic volume with respect to travel time of -0.5 in the shortterm and upto -1.0 in the long-term based on a literature review of induced demand research. This is confirmed by a comparison of forecasted traffic and actual traffic counts taken a year after opening for 151 Department of Transport road projects in the United Kingdom. The actual traffic flows were on average $10.4 \%$ higher than forecast a year after opening. A similar comparison on 85 of the alternative or 'relieved' routes indicated that the observed flows were on average $16.4 \%$ higher than the traffic forecast. While this discrepancy between the traffic forecast and actual traffic counts can be attributed to the errors in forecasting process (other than non-inclusion of induced traffic), the underestimation in traffic flows on the alternative routes that the capacity enhancement were expected to relieve points to the induced traffic error.

\subsection{Evaluation of model performance}

Flyvbjerg (2005) and Flyvbjerg et al. (2005, 2006) conducted one of the most comprehensive studies on inaccuracy in demand forecasts. This statistical study compared the forecast demand with the actual demand for a list of 210 projects between 1969 and 1998. The project list, worth U.S $\$ 59$ billion, was compiled from projects located in 14 countries, both developed and developing, and included both transit (rail) and highway projects. 
The inaccuracy in travel forecasts was estimated as the difference between the actual forecast and the forecasted traffic standardized by the percentage of the forecasted traffic. Actual forecasts were usually counted from the first year of operations or opening year of the facility while the forecasted demand was obtained from the demand estimation produced at the time of decision to go ahead with the project.

The results from the estimation of inaccuracy indicated that forecasts produced for both rail and road projects were significantly misleading. The rail forecasts were highly inflated with passenger forecasts overestimated by two-thirds for $72 \%$ of all rail projects with an average overestimation of 106\%. Inaccuracy in road projects were not as high or one-sided as rail forecasts but $50 \%$ of the road projects showed a $\pm 20 \%$ difference between actual and forecasted traffic. Further the inaccuracies in rail and road forecasts did not improve over time with road forecasts showing greater inaccuracies towards the end of the 30-year study period.

Bain and Polakovic (2005) continued on their previous the tollroad study in 2005 expanding their data set from 87 projects to 104 international toll-road, bridge and tunnel case studies to estimate the ratio of actual to forecast traffic for periods beyond year-one. The preliminary analysis indicated that there was not a systematic improvement in traffic forecasting accuracy beyond year-one with the mean varying between 0.78 and 0.80 and the standard deviation, indicating forecasting error, varying between 0.22 and 0.25 . Further disaggregation of the traffic forecasts by vehicle type indicated a high variability in truck forecasts which in turn contributed to the overall uncertainty.

Wachs (1992) provided some reasons for forecast inaccuracies by exploring the nature of ethical dilemmas in forecasting. Technical experts drawn from the ranks of social scientists, engineers and planners produce most forecasts used to justify investment decisions in transportation. However the complexity inherent in our government structure coupled with limited resources available to policy makers places a huge burden on forecaster to produce self-serving forecasts, while also attempting to maintain objectivity. Since the forecasting process is highly subjective producing consequences of great significance, it becomes rather easy to play with technical assumptions to produce self-serving forecasts.

Kain (1990) talks about the Dallas Area Rapid Transit's (DART) strategic misrepresentation of land-use and ridership forecasting in its campaign to get voters to support the planned 92-mile light rail transit system. This report confirms Wachs's take on the ethical dilemmas that forecasters face wherein decisions taken are not completely objective and are governed by the preferences of the policy makers. Similar to Kain's work in Dallas, Pickrell (1992) conducted a study assessing the accuracy of ridership forecasts and cost estimates for rail projects in eight US cities, namely, Washington, Atlanta, Baltimore, Miami, Buffalo, Pittsburgh and Sacramento. The comparison of costs indicated a uniform trend of gross overestimation of rail ridership forecasts along with an underestimation of the rail construction costs and operating expenses in all the eight cities considered in the analysis.

Richmond (2001) conducted a comparison of rail ridership forecasts to actual ridership as part of his study on evaluating urban transit investments using transit data from US cities and Canada (Ottawa). The analysis indicated that the impact of new rail projects on increasing total transit ridership was minimal and actual ridership in most of the cities considered fell far short of the ridership forecasts available to the decision-maker at the time of deciding to go ahead with the project.

The Federal Transit Administration (FTA) recently conducted a study to analyze predicted and actual impacts of 21 recently opened major transit projects funded under the New Starts program (Lewis-Workman et al., 2007). This study was an extension of two prior studies-the 1990 Urban Mass Transportation Administration study and a 2003 FTA study, looking at projects that opened for revenue service between 1990 and 2002. The ridership analysis conducted as part of this study compared the forecast and actual average weekday boardings and indicated that slightly less than half ( 8 of 18 ) of projects completed between 2003 and 2007 have either achieved or have a good chance of exceeding $80 \%$ of the initial planning level forecasts.

\section{Data}

The forecast traffic data relevant to this analysis was collected from the following Minnesota Department of Transportation (Mn/ DOT) reports prepared in support of the various roadway projects.

- Transportation Analysis Reports (TAR),

- System Planning and Analysis Reports (SPAR),

- Environmental Impact Statement (EIS).

These reports, with a horizon forecast year of 2010 or earlier, focused on the Twin Cities metro area and were collected from various locations, namely, Mn/DOT Central Library, the Collection Department of the State Archives at the Minnesota Historical Society, MnDOT Office of Traffic Forecasting \& Analysis and the MnDOT Metro District Office (Roseville).

Typically, any description of the roadway networks, socioeconomic inputs and other assumptions that went into creating the forecasts were brief. In most cases the assumptions were not provided at all. Further the reports lacked any clear description of the actual roadway project or any explanation as to the need for the report. In general, the forecasts provided in the reports were apparently based on outputs from the Twin Cities regional model altered by ground counts and turning movements taken in the study area.

The actual traffic data used to estimate the inaccuracy in traffic forecasts was obtained from the traffic count database maintained by the Office of Traffic Forecasting \& Analysis Section at Mn/DOT. The data collection efforts for this research project was a intensive and time consuming effort due to lack of proper documentation and proper record keeping procedures. The final database consisted of 108 project reports resulting in a total of 5158 roadway segments in the database and the actual traffic information was obtained for 2984 of the 5158 roadway segments. Fig. 1 shows the geographical locations of the various projects considered in this analysis.

\section{Analysis}

\subsection{Illustrative analysis}

A scatterplot analysis of all the roadway segments in the database comparing actual traffic data to forecast traffic, is provided in Fig. 2 . The target line in the scatterplot shows the ideal condition where the actual traffic data exactly matches the forecast traffic data. From a modeling perspective, it is ideal to have the points in the scatterplot as close to and evenly spread out from the target line as possible. In Fig. 2, the majority of the data points in the scatterplot lie above the target line indicating a significant underestimation trend, meaning forecasted traffic numbers often fall short of actual traffic numbers, especially for higher volumes. 


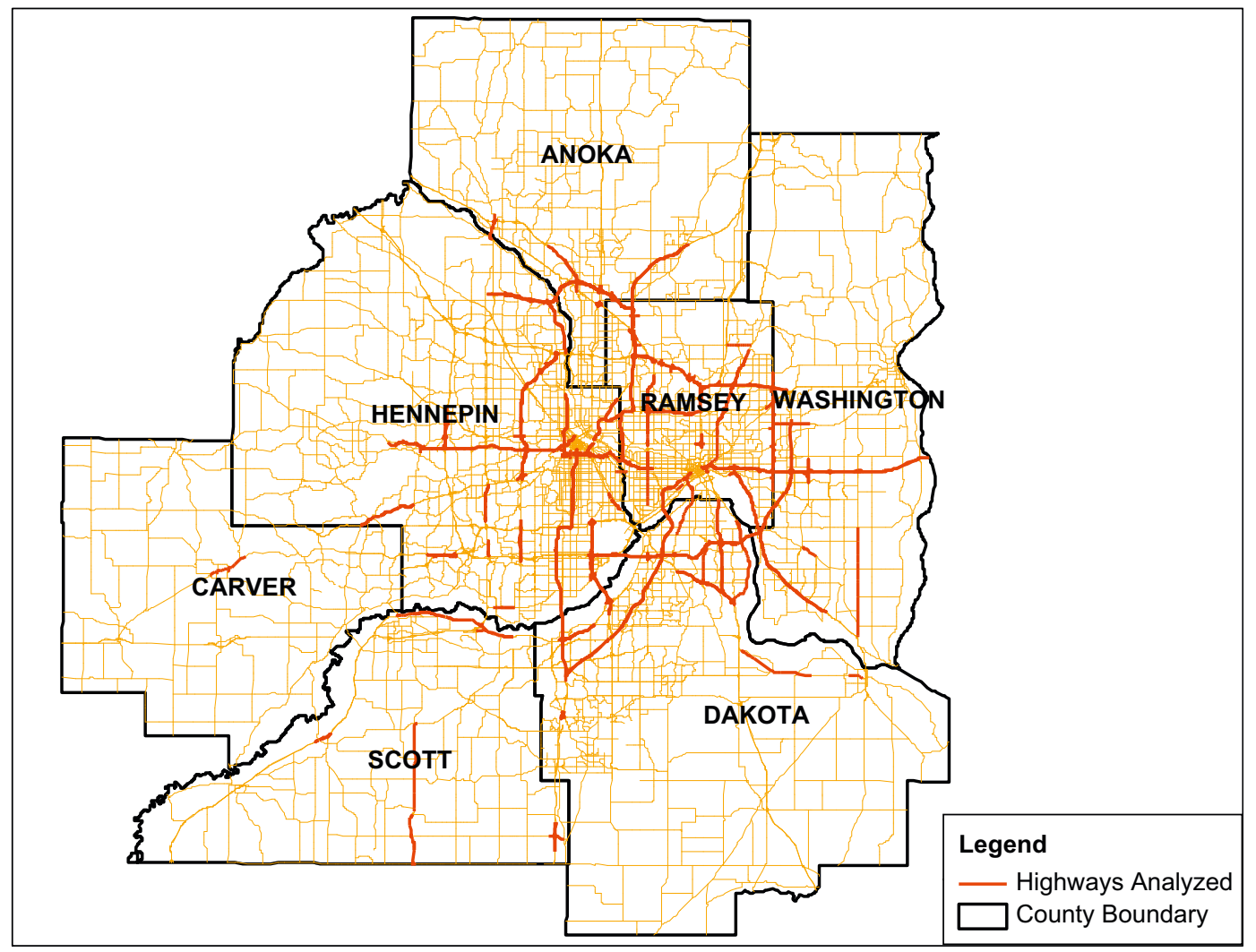

Fig. 1. Geographical location of roadways analyzed.

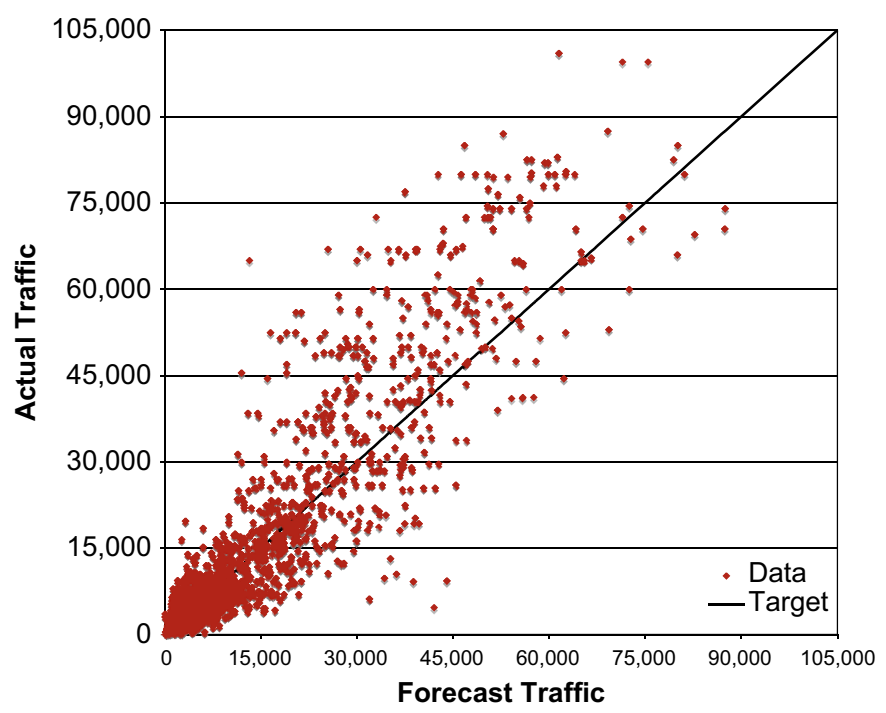

Fig. 2. Scatterplot of actual traffic to forecast traffic.

The inaccuracy in traffic forecasts was estimated as

$I=(F / A)-1$

where $I$ is the estimated inaccuracy in traffic forecasts, $F$ the forecast traffic, $A$ the actual/observed traffic.

A positive inaccuracy value indicates overestimation in the traffic forecasts while a negative value indicates underestimation in traffic forecasts. A value of zero indicates an accurate forecast.

The estimated average inaccuracy by project is presented in Fig. 3. The inaccuracy was estimated for each of the data points in the database with both forecast traffic and actual traffic information and then averaged by project to obtain the average inaccuracy. Table A1 in the Appendix compiles the projects analyzed and the estimated average inaccuracies for each project. The estimation of average inaccuracy shows that the average inaccuracy is less than zero in $47 \%$ of the projects and the average inaccuracy is greater than zero in $49 \%$ of the projects. The estimated average inaccuracy equals zero in $4 \%$ of the projects (within $\pm 0.5 \%$ ).

The average inaccuracy was estimated by different categories to better understand the data and underlying trends. The inaccuracy on critical links, defined here as links with the highest actual traffic, is presented in Fig. 4. This analysis was done to see if these critical links had greater accuracy compared to the other roadways in the project area. The results show a very clear trend of underestimation in the forecasts with $65 \%$ of the critical links showing underestimated traffic forecasts. $27 \%$ of the critical links have overestimated forecast traffic and only $8 \%$ of the critical links have forecast that match the actual counts (within $\pm 5 \%$ ).

The frequency distribution plot of the inaccuracies estimated for the various roadway data points in the database is presented in Fig. 5, and indicates a trend of underestimation. 56\% of the total roadway points in the database are underestimated with inaccuracy less than zero and $44 \%$ of the total roadway points are overestimated with an inaccuracy greater than zero. The highest frequency of $46 \%$ is seen between the ranges of $-0.5-0.0$.

The average inaccuracy by roadway functional classification is presented in Fig. 6 . The roadway segments in the database with forecast traffic and actual traffic data were classified into one of five categories provided below. These classifications were based on the roadway functional classification used in the Year 2000 Twin Cities Regional Travel Demand Model.

- Freeways,

- Undivided Arterials, 


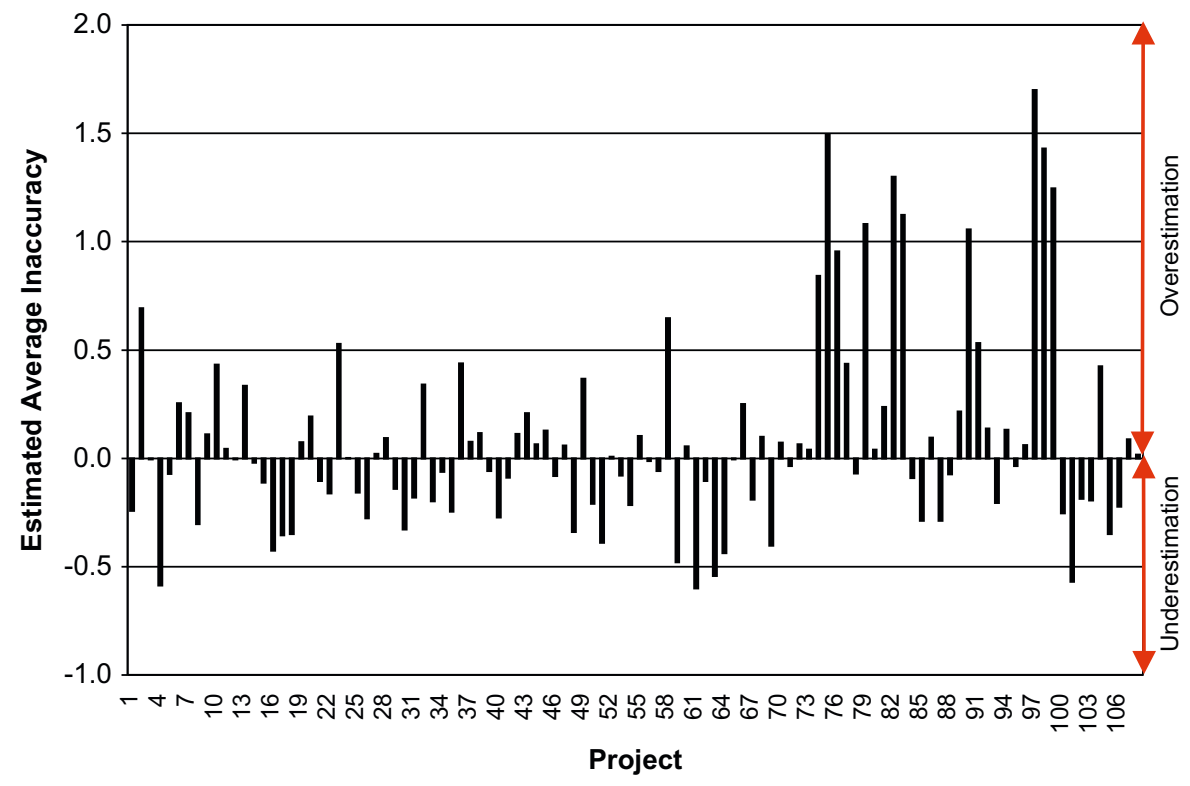

Fig. 3. Estimated average inaccuracy by project.

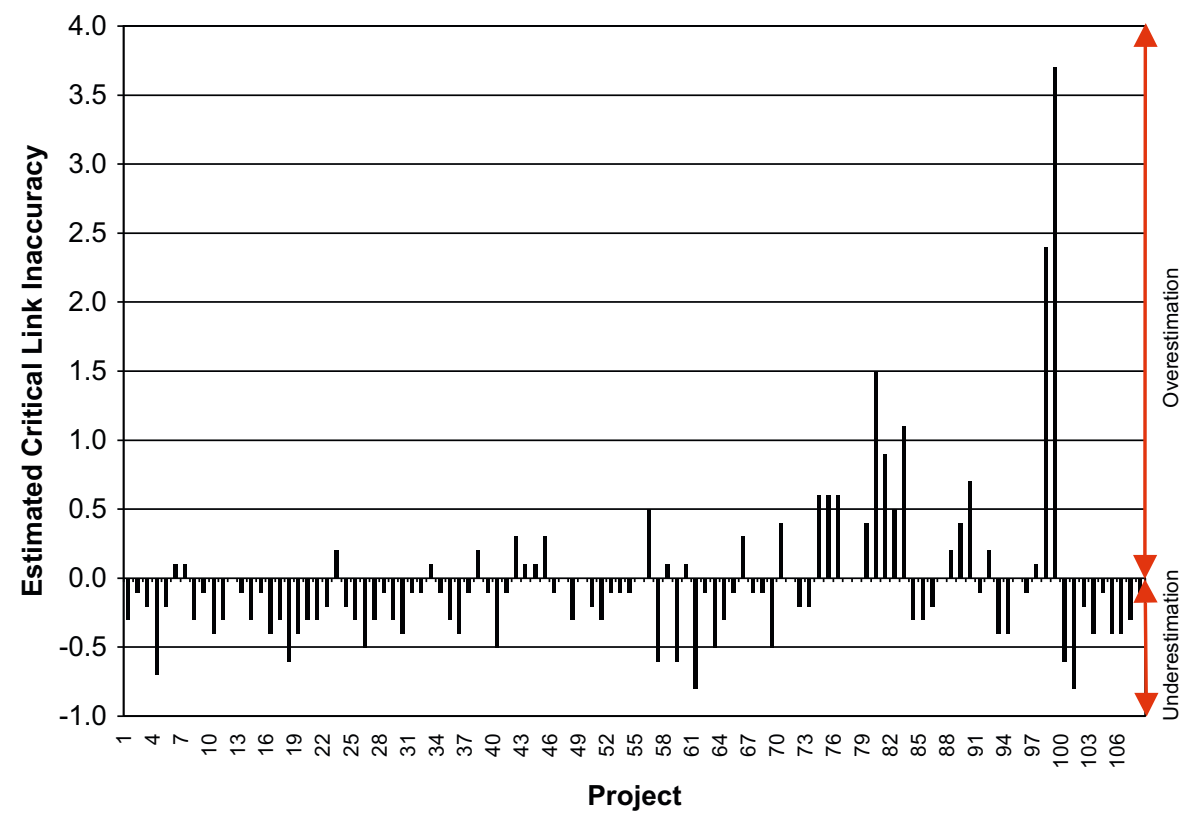

Fig. 4. Estimated inaccuracy on critical links by project.

- Divided Arterials,

- Expressways,

- Collectors.

The inaccuracy was estimated for each data point and then averaged by functional classification to obtain the inaccuracy by functional classification. Fig. 6 indicates that freeways, with an inaccuracy less than zero, are underestimated in traffic forecasts compared to the other roadways functional classifications, which are overestimated.

Fig. 7 represents the average inaccuracy stratified by the count range. This stratification indicates that the higher volume roadways are subject to the problem of underestimation compared to overestimated lower volume roads. Roadways with volumes of 20,000 or less have positive inaccuracy while higher count ranges have negative inaccuracy. This result is in line with the inaccuracy by functional classification since freeways typically carry higher volumes of traffic compared to the other roadways.

Finally the average inaccuracy was estimated for new and existing facilities in the database. This classification is based on the existence/non-existence of the concerned roadway at the time of report preparation, using information from the MnDOT construction project logs and consultations with MnDOT staff. The average inaccuracy for all existing roadway facilities, comprising of $77 \%$ of the projects in the database, was estimated to be 0.20 with the minimum and maximum inaccuracy varying between -0.99 and 7.94 . The average inaccuracy for the new roadway facilities, comprising of $23 \%$ of the projects, was -0.05 with the maximum and minimum inaccuracy varying between -0.84 and 4.00 . This indicates that forecasts on existing 


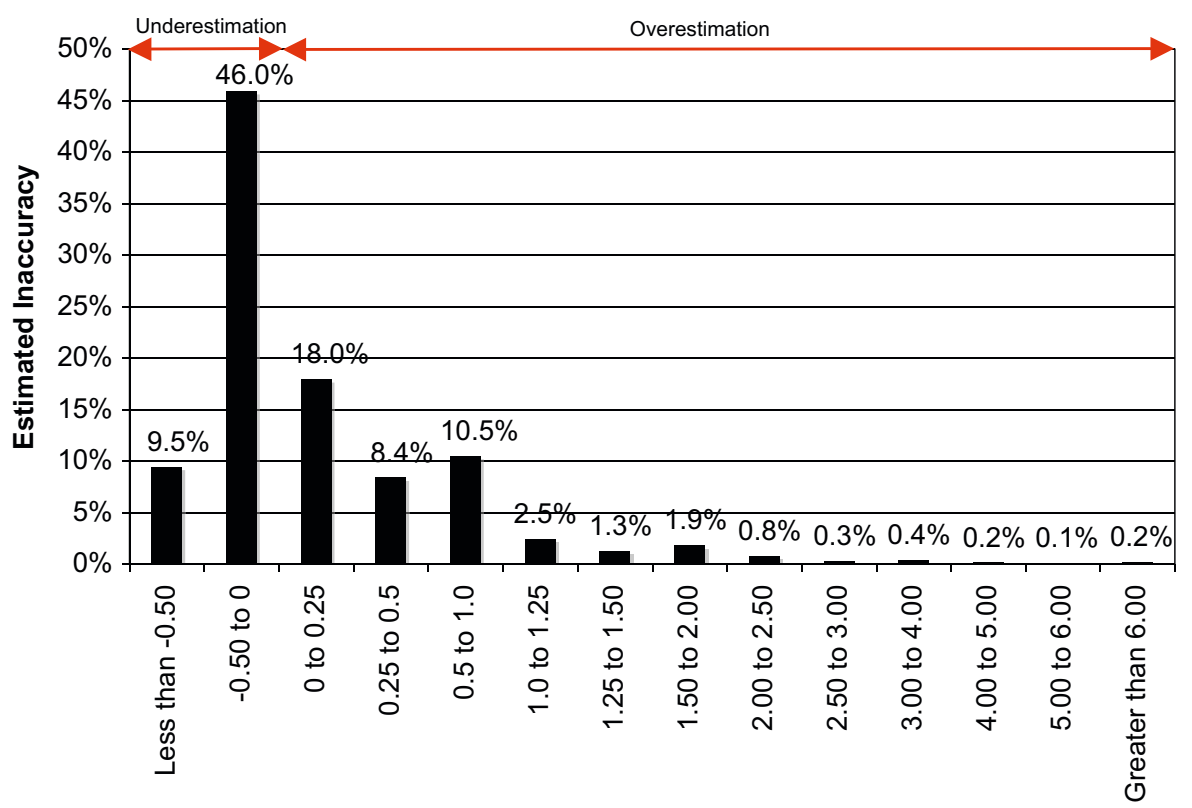

Proportion

Fig. 5. Frequency distribution plot of estimated average inaccuracy.

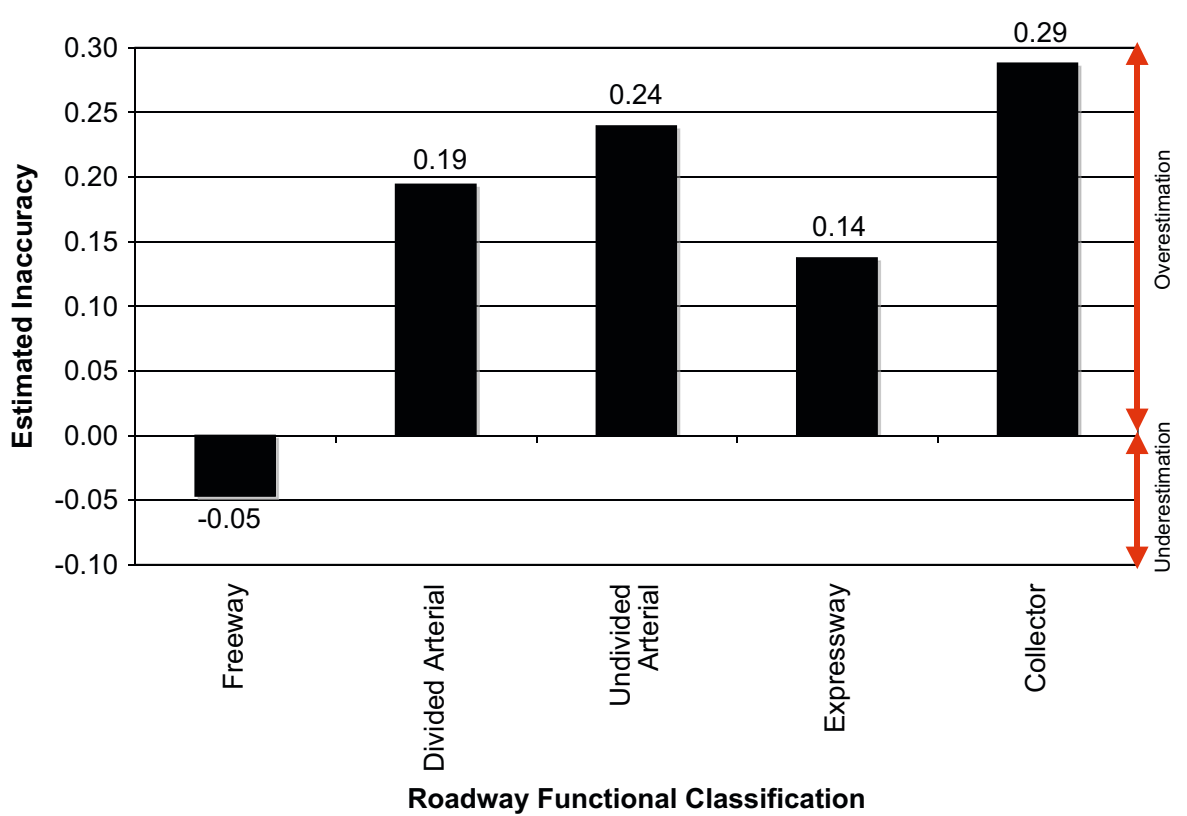

Fig. 6. Estimated average inaccuracy by roadway functional classification.

facilities in the Twin Cities are overestimated compared to new facilities.

The illustrative analysis was conducted to provide a macro level understanding of the database. The results indicate a trend of underestimation in roadway forecasts particularly in roadways of higher volumes and higher functional classifications. The next section on the quantitative analysis will look at the factors that contribute to inaccuracies in traffic forecasts.

\subsection{Quantitative analysis}

As part of the quantitative analysis, a model was developed formulating the inaccuracy in roadway forecasts as a function of certain relevant independent variables. The quantitative analysis used the same data as the illustrative analysis except that it focused only on the main roadway in each project. The analysis did not consider the side streets or other roadways in the project for which forecasts had been provided. The following additional information was collected for each of the main roadway segments in the database with both forecast traffic data and actual traffic data.

- Number of years between the year in which the report was prepared and the forecast year,

- forecast vehicle kilometers traveled (VKT) by project,

- roadway type,

- roadway functional classification,

- roadway segment direction,

- decade of report preparation, 


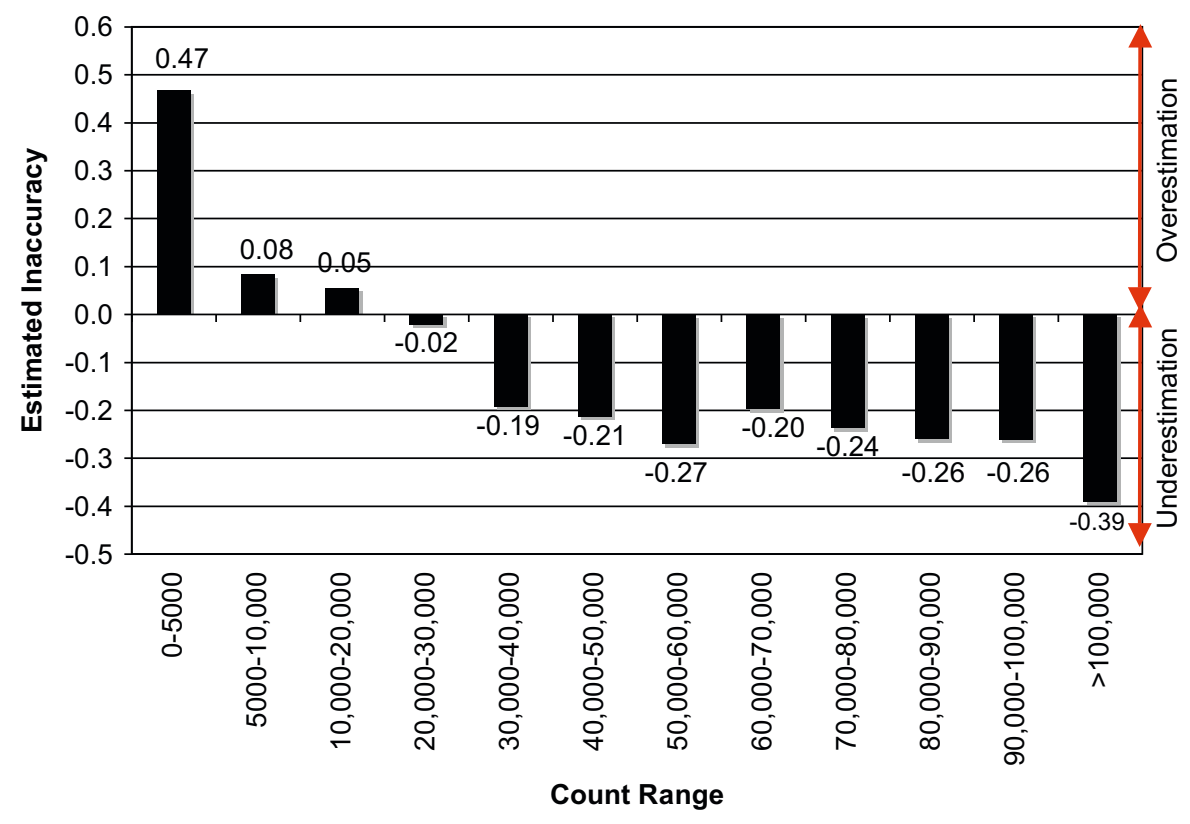

Fig. 7. Estimated average inaccuracy by counts.

- project status (existing/new facility) at the time of report preparation.

The forecast traffic provided on each main roadway segment was multiplied with the segment length, measured as part of this analysis. This estimated forecast VKT on each main roadway segment was then summed up by project to obtain a measure of project size. The main roadways were separated into two roadway types: radial and lateral. Roadways that radiate directly from downtown Minneapolis or St. Paul that could be used as a way to get direct access to the downtowns were classified as radial roadways. The other roadways that do not provide a direct access to the downtown were classified as laterals. For example, in the Twin Cities region, highways such as I-394, I-94, I-35W, I-35E were classified as radial roadways and roadways such as TH 100 , TH 169, TH 51 were classified as lateral roadways.

The roadway functional classification is the same as the one used in the illustrative analysis and is described above in detail. The segment direction was based on the roadway direction with respect to the central cities of Minneapolis and St. Paul. The following segment direction classification was used in this analysis:

- east,

- middle,

- middle north,

- middle south,

- north,

- northeast,

- northwest,

- south,

- southeast,

- southwest,

- west.

In addition, each project was classified into one of the following four time categories based on the year in which the report was prepared.

- 1960-1970 - refers to reports prepared between 1961 and 1970 ,
- 1970-1980-refers to reports prepared between 1971 and 1980 ,

- 1980-1990-refers to reports prepared between 1981 and 1990 ,

- After 1990-refers to reports prepared after 1990.

The main roadways in the database were categorized into existing or new facilities as described previously in the illustrative analysis.

The basic functional form of the regression model estimated is

$I=f(N, H, F, V, D, T, S)$

where $I$ is the Inaccuracy ratio estimated as the difference between the forecast and actual traffic, standardized by the actual traffic, $N$ the Number of years between report year and forecast year, $H$ the Roadway type, $F$ the Functional Classification (used in Model 1 alone), $V$ the Project size measured in VKT, $D$ the Segment direction, $T$ the Time variable representing decade of report preparation, $S$ the Roadway status.

A simple ordinary least squares (OLS) regression model was estimated using the roadway segments that had complete information for all the variables considered in the analysis. In addition to this simple OLS model, also referred to as the basic model, three separate regression models were estimated based on the roadway functional classification. The models thus estimated are:

- Model 1-Entire dataset,

- Model 2-Freeways,

- Model 3-Undivided arterials,

- Model 4-Other, consisting of, Expressways.

Divided Arterials.

Collectors.

The stratification and analysis of the dataset by functional classification in addition to the basic model, was to obtain a better understanding of the causal factors and the variation of their influences by roadway type. The grouping of the expressway, divided arterials and collectors into the other category in the final 
Table 1

Results from OLS regression.

\begin{tabular}{|c|c|c|c|c|c|c|c|c|c|c|c|c|}
\hline \multirow[t]{2}{*}{ Variable } & \multicolumn{3}{|c|}{ Model 1-Entire dataset } & \multicolumn{3}{|c|}{ Model 2-Freeways } & \multicolumn{3}{|c|}{ Model 3-Undivided Arterials } & \multicolumn{3}{|c|}{ Model 4-Other } \\
\hline & Coefficient & $\mathbf{t}$ & Sig & Coefficient & $\mathbf{t}$ & Sig & Coefficient & $\mathbf{t}$ & Sig & Coefficient & $\mathbf{t}$ & Sig \\
\hline \multicolumn{13}{|c|}{ Dependent variable: inaccuracy in roadway forecasts } \\
\hline Number of years & $-3.39 \mathrm{E}-02$ & -9.56 & ${ }^{* * *}$ & $-2.57 \mathrm{E}-02$ & -6.95 & ${ }^{* * *}$ & $-5.72 \mathrm{E}-02$ & -3.92 & ${ }^{* * *}$ & $-7.30 \mathrm{E}-02$ & -8.35 & $* * *$ \\
\hline Project VKT & $-7.47 \mathrm{E}-09$ & -1.43 & & $-5.54 \mathrm{E}-09$ & -0.23 & & $-1.30 \mathrm{E}-08$ & -0.02 & & $-1.22 \mathrm{E}-08$ & -2.25 & ${ }^{*}$ \\
\hline Radial highway type & $-1.08 \mathrm{E}-01$ & -3.33 & ${ }^{* *}$ & $-2.10 \mathrm{E}-01$ & -5.07 & **** & $4.57 \mathrm{E}-01$ & 2.88 & ** & $-8.23 \mathrm{E}-02$ & -1.16 & \\
\hline Collector & $-1.12 \mathrm{E}-01$ & -0.50 & & & & & & & & & & \\
\hline Divided arterial & $4.69 \mathrm{E}-02$ & 0.83 & & & & & & & & & & \\
\hline Expressway & $9.70 \mathrm{E}-02$ & 2.27 & * & & & & & & & & & \\
\hline Undivided arterial & $3.11 \mathrm{E}-02$ & 0.64 & & & & & & & & & & \\
\hline East & $2.64 \mathrm{E}-01$ & 3.23 & ** & $3.47 \mathrm{E}-01$ & 4.01 & ${ }^{* * *}$ & $2.19 \mathrm{E}-01$ & 0.12 & & $2.77 \mathrm{E}-01$ & 1.70 & + \\
\hline Middle north & $-3.61 \mathrm{E}-02$ & -0.49 & & $1.51 \mathrm{E}-01$ & 1.76 & + & $3.19 \mathrm{E}-01$ & 0.78 & & $-4.79 E-02$ & -0.43 & \\
\hline Middle south & $-3.48 \mathrm{E}-01$ & -3.32 & ${ }^{* *}$ & $4.44 \mathrm{E}-02$ & 0.37 & & $-9.54 \mathrm{E}-01$ & -3.09 & ** & $-8.12 \mathrm{E}-01$ & -2.29 & ${ }^{*}$ \\
\hline North & $-1.13 \mathrm{E}-01$ & -1.56 & & $1.53 \mathrm{E}-01$ & 1.90 & + & $1.21 \mathrm{E}+00$ & 3.15 & ** & $-5.13 \mathrm{E}-01$ & -3.73 & $* * *$ \\
\hline Northeast & $5.52 \mathrm{E}-01$ & 7.20 & $* * *$ & $3.68 \mathrm{E}-01$ & 2.73 & ${ }^{* *}$ & $6.57 \mathrm{E}-01$ & 2.41 & ${ }^{*}$ & $7.23 \mathrm{E}-01$ & 6.06 & $* * *$ \\
\hline Northwest & $-1.93 \mathrm{E}-01$ & -2.22 & ${ }^{*}$ & $-5.36 \mathrm{E}-03$ & -0.06 & & $1.32 \mathrm{E}+00$ & 3.19 & ** & $-6.78 \mathrm{E}-01$ & -4.08 & ${ }^{* * *}$ \\
\hline South & $-5.58 \mathrm{E}-02$ & -0.78 & & $1.86 \mathrm{E}-01$ & 2.24 & ${ }^{*}$ & $4.80 \mathrm{E}-01$ & 2.07 & ${ }^{*}$ & $-4.06 \mathrm{E}-01$ & -2.56 & $*$ \\
\hline Southeast & $3.58 \mathrm{E}-01$ & 5.14 & ${ }^{* * *}$ & $8.47 \mathrm{E}-01$ & 8.18 & ${ }^{* * *}$ & $1.63 \mathrm{E}-01$ & 0.80 & & $3.27 \mathrm{E}-01$ & 3.11 & ${ }^{* *}$ \\
\hline Southwest & $-1.62 \mathrm{E}-01$ & -2.05 & ${ }^{*}$ & $1.41 \mathrm{E}-01$ & 1.37 & & $3.51 \mathrm{E}-01$ & 1.15 & & $-3.05 E-01$ & -2.56 & ${ }^{*}$ \\
\hline West & $-1.54 \mathrm{E}-01$ & -1.86 & + & $4.92 \mathrm{E}-02$ & 0.55 & & & & & $1.26 \mathrm{E}-02$ & 0.07 & \\
\hline Report year between 1970 and 1980 & $1.11 \mathrm{E}-01$ & 2.61 & ** & $-1.04 \mathrm{E}-01$ & -1.87 & + & $1.15 \mathrm{E}+00$ & 6.02 & *** & $1.16 \mathrm{E}-01$ & 1.44 & \\
\hline Report year between 1980 and 1990 & $6.38 \mathrm{E}-02$ & 1.35 & & $-2.12 \mathrm{E}-01$ & -3.32 & ** & $-2.37 \mathrm{E}-02$ & -0.16 & & $3.54 \mathrm{E}-01$ & 3.60 & *** \\
\hline Report year after 1990 & $2.78 \mathrm{E}-01$ & 1.26 & & & & & $9.54 \mathrm{E}-01$ & 0.52 & & & & \\
\hline New facilities & $-1.25 \mathrm{E}-01$ & -3.22 & $* *$ & $-1.18 \mathrm{E}-01$ & -3.11 & ${ }^{* *}$ & $-5.27 \mathrm{E}-01$ & -0.30 & & $-2.38 \mathrm{E}-01$ & -2.10 & * \\
\hline Constant & $1.64 \mathrm{E}+00$ & 18.63 & ${ }^{* * *}$ & $5.35 \mathrm{E}-01$ & 5.17 & ${ }^{* * *}$ & $3.28 \mathrm{E}-01$ & 0.95 & & $1.41 \mathrm{E}+00$ & 8.16 & $* * *$ \\
\hline Number of observations & 1275 & & & 745 & & & 185 & & & 345 & & \\
\hline$F(x, x)$ & 19.96 & & & 24.13 & & & 6.01 & & & 11.91 & & \\
\hline Prob $>F$ & 0.0000 & & & 0.0000 & & & 0.0000 & & & 0.0000 & & \\
\hline Adj. $R$-squared & 0.2381 & & & 0.3322 & & & 0.3034 & & & 0.3366 & & \\
\hline
\end{tabular}

Note: Other includes Expressways, Divided Arterials \& Collectors.

${ }^{+} p<0.10,{ }^{*} p<0.05,{ }^{* *} p<0.01,{ }^{* * *} p<0.00$.

regression model (model 4) was to ensure adequacy in sample size.

The results of all the four analyses are provided in Table 1 and identify the factors that influence the inaccuracies in roadway forecasts. A variable which is positive and significant increases the inaccuracy indicating overestimation, while a variable that is negative and significant decreases the inaccuracy ratio resulting in underestimation. The variables that have a significant influence (positive or negative) are identified in Table 1.

The stratification of the data by functional classification did not show major differences in the patterns of influence but indicates significant minor distinctions. The results of the basic model (model 1) alone will be presented here for brevity. We can see that the increase in the number of years between the report year and forecast year results in underestimation of traffic forecasts. Radial roadways are more underestimated compared to lateral roadways in the region. The functional classification of the roadway does not play an influencing role except for expressways which are subject to overestimation with respect to freeways.

Compared to roadways located between the cities of Minneapolis or St. Paul, roadways located in the middle south (between Minneapolis and St. Paul), southwest, northwest and west direction show a trend of underestimation while roadways in the east, northeast and southeast directions show overestimation in traffic forecasts.

The reports prepared in the decade between 1970 and 1980 produced overestimated forecasts compared to the base decade of 1960-1970 but the other time categories do not play an influencing role on forecast inaccuracy. The roadway status (existing/new) at the time of report preparation influences the inaccuracy in forecasts with new facilities underestimated in traffic forecasts compared to the existing roadway facilities. The size of the roadway project does not influence the inaccuracy in forecasts.

The quantitative analysis was conducted to go beyond the illustrative analysis and identify factors that contribute to the underestimation or overestimation in traffic forecasts. While the estimated model was a simple OLS model, the results confirm that the inaccuracy in traffic forecasts is influenced by many factors and also shows the type of influence that each of the variables have on forecast inaccuracy. Both the illustrative analysis and quantitative analysis utilized the actual traffic counts to compare against the forecast traffic. It is important to note that in both these analysis, the actual ground traffic counts need not be $100 \%$ accurate and are subject to their own set of data collection errors. Hence the inaccuracy estimates measured here might vary based on the errors present in the actual traffic information.

\subsection{Qualitative analysis}

Similar to the analysis used by Flyvbjerg et al. (2005), the qualitative analysis involved interviewing modelers in the Twin Cities who have had experience working with the Twin Cities travel demand models. The goal was to obtain their perspectives on the modeling process, which might provide some useful insights into reasons for inaccuracies in forecasting.

A total of seven people were interviewed in this process and the interviews were conducted between May-June 2008. The interviewees varied in terms of their actual hands-on experience with the models and ranged from modelers who were actually involved in the technical development of the model to planners whose expertise were limited to using the results from the model for various roadway projects. The interviews were conducted with 
both private sector consultants and employees of public agencies and conducted either via email and over the phone.

Each of the interviewees were asked a standard set of five questions, which are provided below:

1. your understanding of the possible sources of error in the Twin Cities models,

2. with the current expertise in modeling that we have, what could have be done differently with model development in 1970s, 1980s,

3. how does the Twin Cities model compare with other models that you have worked with or had an opportunity to look at,

4. how would you respond to criticisms against modeling? Many people argue that the most models underestimate/ overestimate the traffic forecasts and hence it is not worthwhile to be spending time, money and efforts on modeling,

5. have there been instances on political compulsions influencing the model forecasting in the Twin Cities?

A complete copy of the seven interviews is not presented here for brevity but a summary of the responses from the interviews are provided below.

While each interviewee provided different reasons for inaccuracies in traffic forecasts, the inability of the model to understand and predict fundamental societal changes was the most often stated reason. The change in the labor force due to increased participation of women was one of the commonly quoted examples of the model's inability to properly account for travel behavior. Other factors such as increases in mobility, auto ownership, influence of the internet and technology on travel were also provided as examples of the model's inability to understand and incorporate societal changes.

Another very important reason often provided by the interviewees were errors in the socio-economic inputs that fed into the model along with the locational distribution of forecasted demographics. The development of socio-economic forecasts used in older models was done exclusively by the Metropolitan Council and $\mathrm{Mn} / \mathrm{DOT}$ without any input from local communities. The involvement of local communities in the 1990s helped correct this error to a certain extent. However, community participation introduced new errors into the modeling process due to aggressive forecasting by local communities, without any thought as to where the growth should be allotted or any understanding of ways to meet the infrastructure requirements of the forecasted population and employment. It is only in the last $8-10$ years that communities have started to understand the importance of realistic socio-economic forecasts. The difference between planned and actual highway network construction was also provided as another reason for inaccuracy in forecasts.

The technical and computational limitations in the older models made it difficult for modelers to track errors, conduct sensitivity tests etc. to ensure the reasonableness and accuracy of their forecasts. The complicated nature of the models also resulted in limited oversight to a select few individuals, which meant fewer discussions and fewer people looking at the model forecasts to ensure reasonableness.

From a technical standpoint, the trip distribution model came in for criticism because a basic understanding of the basic trip patterns in the region is still lacking. Other technical aspects of the model criticized by interviewees, include the assigned importance of home based work (HBW) trips compared to other purposes, traditional focus on principal arterials with little importance to assignment on collectors/minor arterials, inability of the model to handle peak spreading and the assumption of a fixed percentage of daily traffic for the peak periods and the handling of special generators, especially big ones such as the Mall of America.

The interviewees agreed that, compared to other regions, political compulsions were less of a major influencing factor in traffic forecasts for the Twin Cities. Some of the interviewees indicated that in terms of model input assumptions such as roadway capacities, socio-economic inputs, private consultants were more likely than public employees to face pressure from the clients. Public agencies in the Twin Cities face less political pressure, however, sometimes there is a "push" to use existing or expected assumptions which may not sync with the data in hand.

All interviewees agreed models were required for accurate forecasting. The view of the interviewees was that criticisms against the use of modeling in forecasting arises when, for example, results are used by policy makers who lack an understanding of the process behind the numbers or when policy makers apply a macro level model to a micro level study area without adequate changes to the parameters of the model given the difference in the scale of analysis. Additionally issues arise from the lack of understanding that models are best used for highlighting differences between various scenarios rather than providing absolute numbers. The interviewees also argued that models need to be looked at as only one of many tools to help in the decision making process. Use of alternative techniques to models, such as growth rates, will work only in few scenarios. Hence models are absolutely essential to forecasting the future.

\section{Understanding reasons for forecast inaccuracy}

One of the primary objectives in this research was to test for the presence of inaccuracy in roadway traffic forecasts using Twin Cities data. Another important objective of this research was to identify the reasons for the presence of inaccuracy in traffic forecasts. Such an analysis would ideally involve looking at input assumptions (roadway network, socio-economic forecasts, trip rates etc.) that went into creating the forecasts for each of the projects in the database. The difficulties encountered in the data collection efforts of this research project combined with minimal documentation provided in each project report, and finally the inability to obtain actual model files from 1970 and 1980 models highlighted the in-feasibility of such an approach.

Rather than attempt to collect the input information for each of the project reports in the database, it was decided to collect input information that might have been used in the regional travel demand model to prepare forecasts. As indicated in the above data section, most forecasts in the database were prepared based on the regional travel demand models, modified by ground counts and turning movements. So comparing model inputs to actual numbers would help shed light on the reasons for forecast inaccuracy.

In the quantitative analysis, errors in the socio-economic inputs that feed into the model along with the locational distribution of forecasted demographics were identified as important reasons for forecast inaccuracy. Some of the interviewees indicated that the demographic forecasts were overoptimistic especially in the 1970s, when forecasts were governed by the Metropolitan Council's growth objective of " 4 million by the year 2000".

Table 2 provides a comparison of demographic forecasts to the actual numbers, estimated as an inaccuracy ratio. The demographic forecasts were prepared by Metropolitan Council for the 7-county metro in March 1975 for future years 1980, 1990 and 2000 and used in the respective regional travel demand models. The actual Census demographics for Minnesota was obtained from the datanet hosted at the Minnesota Land 
Table 2

Comparison of demographic forecasts.

\begin{tabular}{|c|c|c|c|}
\hline $\begin{array}{l}\text { Average inaccui } \\
\text { County }\end{array}$ & $\begin{array}{l}\text { etropolitan counci } \\
1980 \text { Population }\end{array}$ & 1990 Population & 2000 Population \\
\hline Anoka & 0.08 & 0.01 & -0.07 \\
\hline Carver & 0.02 & 0.19 & 0.04 \\
\hline Dakota & 0.17 & 0.19 & 0.19 \\
\hline Hennepin & 0.10 & 0.08 & 0.06 \\
\hline Ramsey & 0.12 & 0.17 & 0.22 \\
\hline Scott & 0.02 & 0.04 & -0.11 \\
\hline Washington & 0.11 & 0.27 & 0.22 \\
\hline Total 7-county & 0.11 & 0.12 & 0.10 \\
\hline
\end{tabular}

Table 3

Summary of travel behavior inventory (TBI) data.

\begin{tabular}{|c|c|c|c|c|c|c|c|c|}
\hline \multirow[t]{2}{*}{ Variables } & \multicolumn{6}{|c|}{ Travel behavior inventory data } & \multicolumn{2}{|c|}{ Percentage change } \\
\hline & 1949 & 1958 & 1970 & 1982 & 1990 & 2000 & $1990-1970(\%)$ & 2000-1970 \\
\hline HBW average trip length: miles & na & na & 6.6 & 8.1 & 9.2 & 11.4 & $40 \%$ & $74 \%$ \\
\hline HBW average trip time: minutes & na & na & 19.8 & na & 21.2 & 25.6 & $7 \%$ & $29 \%$ \\
\hline Trips per capita & 1.8 & 2.5 & 2.7 & 3.4 & 3.9 & 4.2 & $43 \%$ & $54 \%$ \\
\hline Trips per household & na & 7.5 & 8.9 & 9.1 & 10.1 & 10.3 & $14 \%$ & $16 \%$ \\
\hline Persons per household & na & na & 3.3 & 2.7 & 2.6 & 2.5 & $-22 \%$ & $-25 \%$ \\
\hline Workers per household & na & na & 1.3 & 1.4 & 1.4 & na & 9 & na \\
\hline Auto occupancy: HBW & 1.1 & 1.1 & 1.2 & 1.2 & 1.1 & 1.1 & $-10 \%$ & $-12 \%$ \\
\hline Auto occupancy: overall & 1.6 & 1.6 & 1.5 & 1.3 & 1.3 & 1.4 & $-14 \%$ & $-10 \%$ \\
\hline Percentage of women in labor force* & na & na & $49 \%$ & $60 \%$ & $68 \%$ & $73 \%$ & $39 \%$ & $49 \%$ \\
\hline
\end{tabular}

"Source: 2005 Twin Cities Transportation System Performance Audit.

Management Information Center (LMIC) and the National Historical Geographical Information System (NHGIS) (Land Management Information Center, 2008; Minnesota Population Center, 2008).

The comparison indicates a trend of overestimation in demographic forecasts with all counties showing an inaccuracy ratio of greater than zero except for the year 2000 forecasts for fast growing suburban Anoka and Scott counties. The results from the comparative analysis indicate the presence of errors in the demographic forecasts used in the travel demand models, which may have contributed to the inaccuracy in the roadway forecasts.

Another component of the modeling process that may have contributed to the overall inaccuracy in traffic forecasts is the trip generation/travel behavior component. The regional travel demand models used in the Twin Cities are typically based on the Travel Behavior Inventory (TBI) survey. The TBI is a Twin Cities comprehensive travel survey conducted jointly by the Metropolitan Council and Mn/DOT about every 10 years. The travel characteristics estimated from the TBI are used to update the regional travel demand model for forecasting purposes (Metropolitan Council of the Twin Cities Area, 2003).

Since it was not possible to obtain the actual model files from the 1970s and 1980s, we instead looked into the TBI data for an understanding of travel behavior characteristics used in the models to produce forecasts. Table 3 provides a summary of the TBI data from 1949 to 2000. It can be seen that the average homebased work (HBW) trip length, trips per capita and trips per household show an increasing trend while the auto occupancy and persons per household show a decreasing trend.

The regional travel demand models were developed based on the actual TBI data for the base year and typically used similar travel characteristics for the forecast year. So a 1990 traffic forecast prepared using the 1970 travel demand model would use travel characteristics from the 1970 TBI for the base year traffic and characteristics similar to 1970 TBI for 1990 traffic forecasts. The 1970 model used to prepare 1990 traffic forecasts would most likely not have incorporated the following changes between 1970 and 1990, given below:

- a $40 \%$ increase in home-based work (HBW) trip lengths,

- a steep increase in trip making characteristics-a $43 \%$ increase in trips per capita, a $14 \%$ increase in trips per household, a $39 \%$ increase in women labor force participation,

- a $22 \%$ decrease in persons per household combined with a $9 \%$ increase in workers per household,

- a $10 \%$ decrease in HBW auto occupancy and a $14 \%$ decrease in overall auto occupancy.

The inability of travel demand models to incorporate such fundamental shifts in travel behavior could be an important reason for inaccuracy in traffic forecasts.

Another possible reason for inaccuracy in roadway traffic forecasts could be the differences between the assumed highway network and the actual in-place network. Most roadway projects suffer a gap between the planning stage and actual construction/ implementation stage, which is magnified by delays encountered during actual roadway construction. In addition, roadway alignment plans undergo many changes. The initially analyzed alignment might be very different from the actual in-place alignment. In some cases, forecasts include the presence of entire roadways that fail to be constructed within that forecast year.

It was not possible to identify the roadway network assumptions for each project report in the database. Therefore we decided to conduct a macro-level analysis by comparing the network assumptions from the Transportation Policy Plans (TPP) and other comprehensive plans against the actual year of roadway construction. The TPP is prepared by the Metropolitan Council as part of the comprehensive development guide also called the Regional Development Framework (RDF) for the Twin Cities seven-county metropolitan area. The TPP describes the transportation policies and plans that the Metropolitan Council plans to implement 
Table 4

Comparative analysis of highways identified in the 1976 regional development framework.

\begin{tabular}{|c|c|c|c|}
\hline Highways $^{\mathrm{a}}$ & From & To & Year built \\
\hline $\mathrm{I}-35 \mathrm{E}$ & West Seventh Street & $\mathrm{I}-94$ & 1984-1991 \\
\hline $\mathrm{I}-35 \mathrm{E}$ & $\mathrm{I}-35$ & State Highway 110 & 1981-1985 \\
\hline I-94 (Mpls) & US 12 & 57th Ave N & $1980-1982$ \\
\hline $\mathrm{I}-494$ & State Highway 5 & $\mathrm{I}-494$ & $1982-1986$ \\
\hline US 10 & Ramsey Co Rd J & State Highway 47 & 1990 \\
\hline US 169 (W River Rd) & 86th Ave N & Northtown Corridor & 1983 \\
\hline US 169/ State 101 (Shakopee Bypass) & US 169 & State Highway 13 & 1976-1980 \\
\hline US $169 / 212$ & I-494 & State Highway 41 & 1994-1996 \\
\hline Co Rd 18 (Hennepin) & 5th Street S & Minnetonka Blvd & 1994 \\
\hline Co Rd 62 (Hennepin) & Co Rd 18 & I-494 & 1985-1986 \\
\hline Northtown Corridor & US 169 & I-94 & Not built yet \\
\hline Northtown River Crossing & US 10 & US 169 & 1998 \\
\hline LaFayette Expressway (52) & I-494/State Highway 110 & State Highway $55 / 52$ & $1985-1994$ \\
\hline I-335 & I-94 & I-35W & Control Section eliminated in 1979 \\
\hline
\end{tabular}

${ }^{\text {a }}$ New facilities expected to be constructed to complete the 1990 Metropolitan highway system.

between the plan's adoption year and the plan's forecast year to meet the regional goals of the RDF. The Metropolitan Council's current 2030 Transportation Policy Plan was approved and adopted by the council on December 15, 2004 (Metropolitan Council of the Twin Cities Area, 2004).

Table 4 provides a comparison of the roadways identified in the $1976 \mathrm{RDF}$ and expected to be completed by 1990 against the actual year of construction of each roadway. These highway network assumptions would have been used in the regional travel demand models to produce forecasts for 1990 and later.

The rows highlighted in bold in Table 4 are highways that did not get completed by 1990 and in some cases ended up not being built at all. For example, the I-335 alignment, proposed in the 1976 RDF, between I-94 and I-35W, has been eliminated from consideration by Mn/DOT and there are currently no plans to construct this section. Similarly the section of Northtown Corridor between I-94 and US 169 has still not been completed even though it was identified to be completed by 1990 . The differences between assumed networks and planned networks arise, namely because of construction delays, funding issues, public opposition, shift in regional planning goals etc. Nevertheless, such differences between assumed networks and in-place networks contribute to the inaccuracy in project forecasts.

This macro-level analysis indicates that the inaccuracies in roadway forecasts arise from different sources, some of which have been described above. While the difficulties in data collection limited the type of detailed analysis that could have been otherwise conducted, the results highlight the differences between forecasted and actual inputs that feed into the model forecasting process, which consequently result in forecast errors.

\section{Conclusions}

The objective of this study was to use Minnesota data to estimate the inaccuracy present in roadway forecasts and identify the reasons for inaccuracy. The illustrative analyses indicated a trend of underestimation in roadway forecasts. This was especially true in the case of higher volume roadways and higher functional classification roadways, such as freeways. A simple OLS model shed light on the factors influencing forecast inaccuracy and the pattern of influence of each variable on overall traffic inaccuracy. Variables such as the number of years between the report year and forecast year, roadway functional classification, roadway direction, year of report preparation and roadway status significantly underestimated traffic forecasts.

The qualitative analysis helped identify, from a modeler's perspective, possible sources of inaccuracy in traffic forecasts. Identified errors in model inputs such as demographic forecasts, trip making characteristics and network differences all contribute to the total inaccuracy in roadway forecasts, though the extent of any one variable's contribution is difficult to estimate with the data available. Modeling methodologies such as the use of capacity constraints, improvements in equilibrium assignment techniques, and mode choice routines change over time, which increases methodological inconsistencies that also contribute to the differences in roadway traffic forecasts prepared over various years.

The data collection efforts on this research project were much more laborious and time consuming than anticipated. The unavailability of the data in electronic format, lack of proper documentation, poor record keeping and data archiving procedures complicated the data collection process and subsequent analyses. Many of the older model files were in paper format and disappeared from the archives, compounded by the turnover in office personnel and changes in office venues.

Based on experiences conducting this study, one of the most important recommendation we can make, is to emphasize the benefits gained by agencies when record keeping and data archiving procedures are consistent and up-to-date. A documented history would make it easy to look back at the modeling process (inputs, assumptions, technical methods); thus much more could be learned from other types of analyses (sensitivity analysis, backcasting procedures) in investigating the reasonableness of traffic forecasts.

By nature of any process that looks at the long-term health of a system, the forecasting task is a complicated one. It is especially difficult to anticipate changes or control for errors in model forecasts. In some cases, it is almost impossible to predict or incorporate factors outside the control of the planning agency. For example, the worldwide financial crises or threats to national security are known to influence the travel patterns of individuals; nevertheless, it is not easy to know to what extent these issues will be a problem in future years.

Societal changes such as improvements in technology, internet use and rising gas prices contribute to changes in the way people travel and make residential and employment decisions. Most modelers interviewed as part of this research acknowledged the lack of a proper understanding of travel behavior and trip distribution could be possible sources for model errors. The 


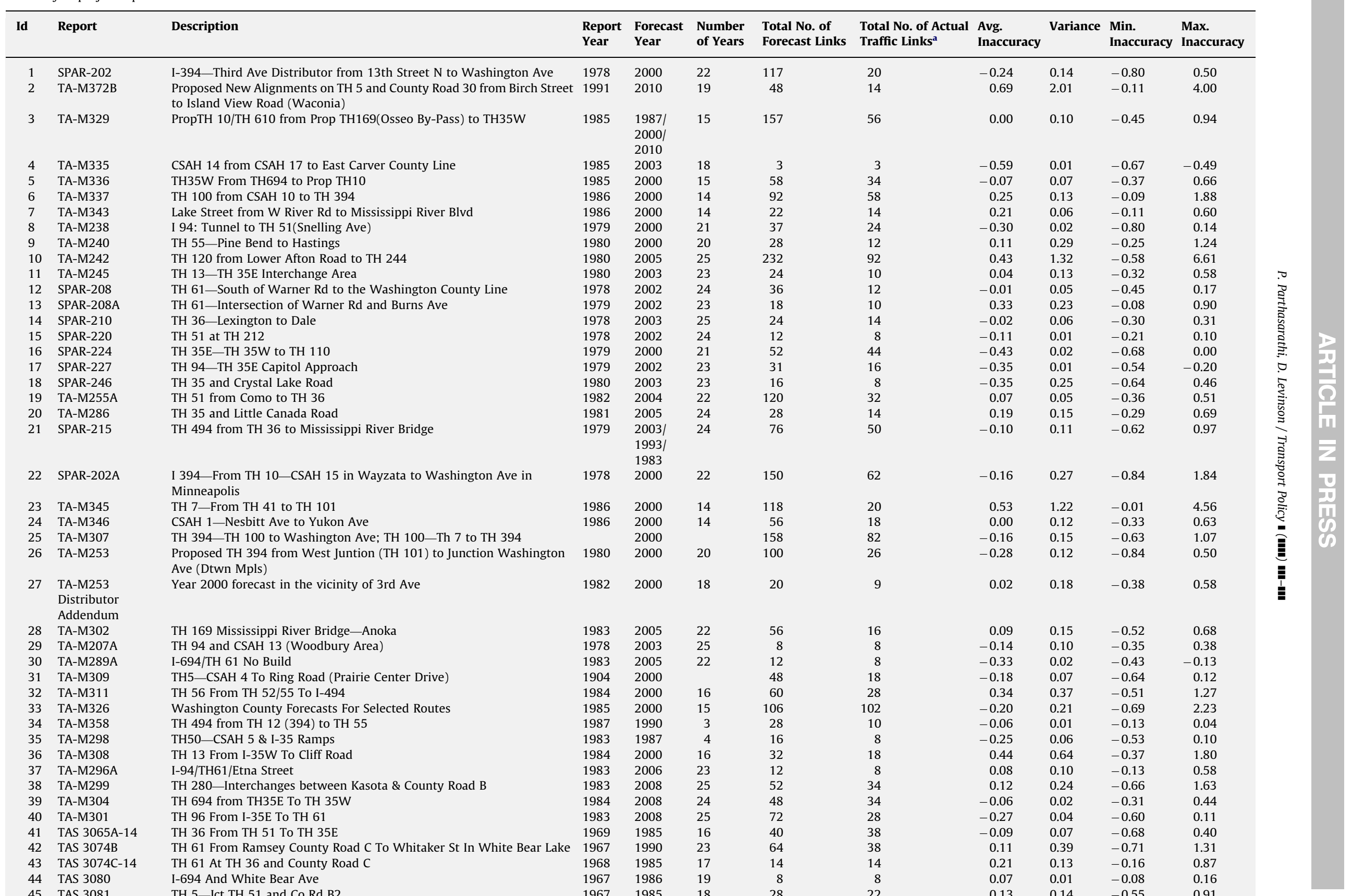


TAS 3066A-14 TH 94 Victiry Osixh Street in St. Paul

50 TA-M292

52 TAU 3066

Airport South Study (TH77, I-494, TH5)

TH 36 at Hamline Ave

6756

53 TAU 3069

54 TAU 3070

56 TAU 3073A

7 TAU 3074

5 TAU 3074A

$\begin{array}{ll}59 & \text { TAU } 3075 \\ 60 & \text { TAU } 3076\end{array}$

60 TAU 3076

62 TAU 3078

63 PSU3203A

64 PSU3203B

65 TAS3081B-14

$\begin{array}{ll}66 & \text { TAS3082-14 } \\ 67 & \text { TAS3084-14 }\end{array}$

67 TAS3084-14

68 TAS3085-14

70 TAU 3205

71 TAU 3223

72 TAU $3451 \mathrm{~A}$

74 SPARS 2

75 SPARS $2 \mathrm{~A}$

76 SPARS 3

7 SPARS 4

78 SPARS 15

79 SPARS 16

80 SPARS 17

81 SPARS 18

82 SPARS 19

83 SPARS 32

84 SPARS 33

$85 \quad$ SPARS 37

86 SPARS 45

87 SPARS 48

88 SPARS 49

89 SPARS 53

90 SPARS 60

90 SPARS 60

91 SPARS 6

92 SPARS 65

93 SPARS 69

94 SPARS 72

95 SPARS 73

96 SPARS 75

97 SPARS 75A

$\begin{array}{ll}98 & \text { SPARS } 77 \\ 99 & \text { SPARS } 78\end{array}$

TH 94-Pillsbury Street To Snelling Ave in St. Paul

TH 35E-Maryland Ave Interchange

TH35E-TH694 To North Ramsey County Line

TH 96-TH35E to TH 61

TH61-From I-94 to TH 212

TH61 - From TH36 to . 4 mi North Of County Road C

TH8-From Northeastern Junction Of I-35W to Stinson Blvd.

Half Cloverleaf Interchange At TH 51 and County Road B-2

TH 5-Toronto Avenue to Banfil Street in St. Paul

TH 280 - Kasota Ave Interchange, and West Frontage Rd, and Connectir Ramps

TH101/13 - West City line of Shakopee to .21 miles West of City Line of 1962 Savage

TH13-TH101 West Of Savage To 75 Mi West Of I-35W

TH51-TH36 to Hamline Avenue

[-94-From Mounds Boulevard To I-494/694

TH280-From Franklin Avenue To NPRR Bridge

University Avenue-Park Street To Marion Street

TH13-TH19 East Of New Prague to TH 282 North Of Lydia (Scott

I-35-From South Scott County Line to CMSTP\&P Railroad

TH10-From Elk River To Big Lake

I-94-From I-494/694 To .5mi East Of CSAH 19

I-94-From 5Mi East Of CSAH 19 to the St. Croix River

TH 212-TH 120 to proposed CSAH 19, I-69-Temporary TH 212 To

County Road 68

TH 212-TH 120 to proposed CSAH 19, I-694-Temporary TH 212 To County Road 68

TH52-Pine Bend to Proposed TH 61 near Hastings

TH 61-From I-494 to County Road F

TH 169-From I-494 to CSAH 61

TH 55 and 52- From TH 49 to TH 56

TH 56-From Linden Street to CSAH 26

TH 56 - From Richmond St. to Grand Ave.

[-494/I-694-From Mississippi River to TH 212 (TH 5)

TH 3-From TH 52 and TH 55 to Salem Church Rd.

TH 51(Snelling Ave.)-From I-94 to Pierce-Butler Route

TH 10, Jct. TH 10 with TH 96 and I-35W with TH 96

TH 51 (Snelling Ave.)-From TH 5 to Pierce Butler Route

TH 169-From TH 282 to $\mathrm{TH} 21$

TH 10-From Egret Boulevard to University Ave. in Coon Rapids

I-35E-From W. 7th St. to Kellog Blvd.

TH 61-From I-494 to County Road 19

CSAH 18-From Smetana Rd. to CSAH 3

TH 10-From Egret Blvd. to University Ave.

TH 100-From I-494 to Benton Ave.

From Dowing Ave, to TH 12

TH 10—Proposed Cloverleaf Junction for TH 65

TH 52-From Mendota Rd. to Annapolis St.

TH 49 (Dodd Rd.) - From TH 110 to I-35E

TH 95-From TH 61 to CSAH 18

$\begin{array}{rrrr}-0.08 & 0.11 & -0.33 & 0.96 \\ 0.06 & 0.15 & -0.56 & 0.83 \\ -0.34 & 0.07 & -0.64 & 0.15 \\ 0.37 & 0.24 & -0.19 & 1.16 \\ -0.21 & 0.08 & -0.74 & 0.69 \\ -0.39 & 0.03 & -0.68 & -0.27 \\ 0.01 & 0.18 & -0.37 & 1.28 \\ -0.08 & 0.00 & -0.12 & -0.06 \\ -0.22 & 0.01 & -0.29 & -0.14 \\ 0.10 & 0.05 & -0.29 & 0.54 \\ -0.01 & 0.15 & -0.46 & 0.45 \\ -0.06 & 0.30 & -0.59 & 0.59 \\ 0.65 & 0.39 & -0.09 & 1.60 \\ -0.48 & 0.02 & -0.58 & -0.29 \\ 0.06 & 0.08 & -0.20 & 0.46 \\ -0.60 & 0.04 & -0.79 & -0.36 \\ -0.10 & 0.00 & -0.13 & -0.06 \\ & & & \\ -0.54 & 0.00 & -0.62 & -0.49 \\ & & & \\ -0.44 & 0.02 & -0.62 & -0.27 \\ 0.00 & 0.12 & -0.36 & 0.96 \\ 0.25 & 0.26 & -0.70 & 1.36 \\ -0.19 & 0.01 & -0.35 & -0.07 \\ 0.10 & 0.11 & -0.32 & 0.76 \\ -0.40 & 0.08 & -0.66 & 0.12 \\ 0.07 & 0.19 & -0.48 & 0.52 \\ -0.04 & 0.56 & -0.99 & 0.90 \\ 0.06 & 0.14 & -0.26 & 0.63 \\ 0.04 & 0.43 & -0.48 & 1.32 \\ 0.84 & 0.85 & -0.16 & 2.20 \\ & & & \\ 1.49 & 1.91 & -0.16 & 3.59 \\ & & & \\ 0.95 & 0.29 & 0.01 & 1.68 \\ 0.44 & 1.31 & -0.84 & 6.82 \\ -0.07 & 0.17 & -0.78 & 0.65 \\ 1.08 & 2.43 & -0.54 & 5.70 \\ 0.04 & 0.25 & -0.37 & 1.48 \\ 0.24 & 0.18 & -0.24 & 1.02 \\ 1.30 & 0.90 & 0.24 & 4.31 \\ 1.12 & 0.60 & -0.30 & 2.39 \\ -0.09 & 0.08 & -0.51 & 0.57 \\ -0.29 & 0.04 & -0.76 & -0.08 \\ 0.09 & 0.16 & -0.49 & 1.04 \\ -0.29 & 0.12 & -0.75 & 0.04 \\ -0.07 & 0.16 & -0.68 & 0.44 \\ 0.22 & 0.13 & -0.43 & 0.66 \\ 1.06 & 2.21 & -0.38 & 5.92 \\ 0.53 & 0.76 & -0.48 & 2.44 \\ 0.14 & 0.03 & -0.19 & 0.32 \\ -0.20 & 0.03 & -0.41 & 0.17 \\ 0.13 & 0.25 & -0.64 & 1.08 \\ -0.04 & 0.02 & -0.15 & 0.14 \\ 0.06 & 0.21 & -0.60 & 1.36 \\ 1.70 & 7.97 & -0.40 & 12.78 \\ 1.43 & 0.62 & 0.24 & 2.50 \\ 1.25 & 2.16 & -0.29 & 3.69\end{array}$




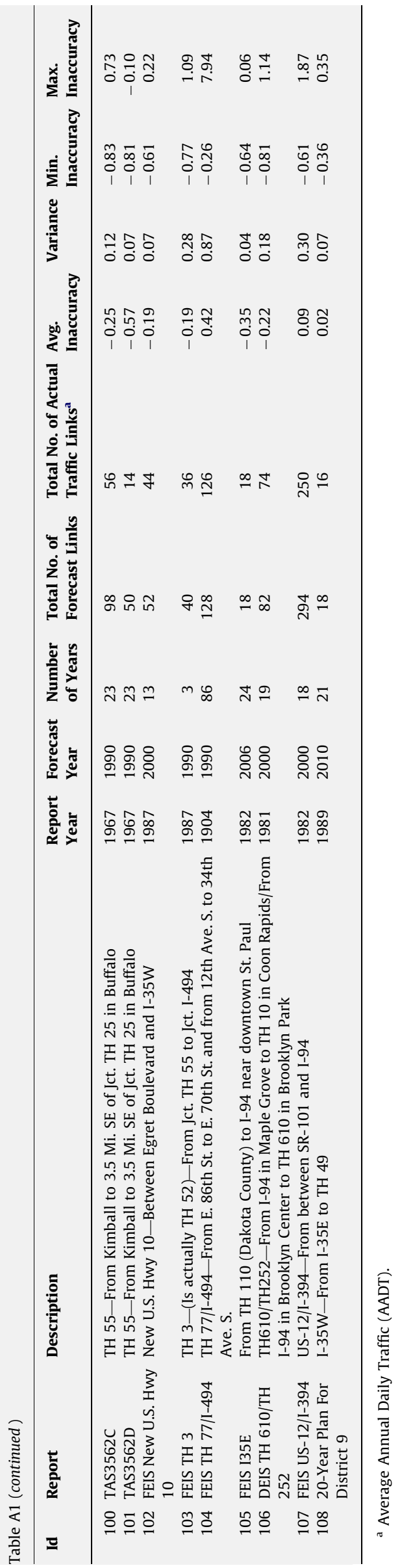

impact of fundamental societal changes on traffic forecasts and the dependence of irreversible infrastructure decisions on these forecasts makes it imperative for modelers to better understand them and incorporate them rather than blindly utilizing existing trends into the forecasting process. For example, analysis of recent labor force data show increasing participation of older men and women (65 years and above) in the labor force (Gendell, 2008). The data not only shows increase in worker participation rates but also increasing full-time employment rates for this $65+$ age group. This finding reverses the long run decline in employment for this age group and will have implications on travel as the percentage of older adults in the work force increases.

From a modeler's perspective, it would really help for nonmodelers/decision makers in charge of funding decisions to obtain a better understanding of the forecasting process before making decisions based on model results. Most interviewees in this analysis acknowledged that a basic understanding of the science behind the forecasts, limitations and applicability of traffic forecasts would go a long way in diffusing criticisms against modeling. Some of the issues in the current scenario are the absence of any clear scientific approach in modeling, lack of transparency in the modeling process and lack of proper evaluation of alternatives. There is significant effort expended in developing the models but not much in the way of evaluating, interpreting and explaining the model results.

Modeler's develop travel demand models based on their intrinsic assumptions, knowledge and predictions of human behavior. These assumptions and predictions about future conditions are based on the available past and present data. The use of forecasts to justify policy decisions results in a reversal of "causeand-effect", where present decisions are based on predictive future events. As Robinson (1988) points out, this approach is underlined with paradoxes and the consequences of such paradoxes are typically ignored in the attempts to predict the future. This calls for a fundamental rethinking of the meaning, purpose and use of forecasting and modeling methodologies and a move towards adopting a comprehensive view rather than a narrow project related focus. Instead of expecting models to predict the most likely future, Robinson (1988) calls for the use of techniques that can provide us with different possibilities and impacts of the alternative futures.

The philosophical, institutional and methodological nature of modeling makes it extremely difficult to predict future conditions in an unbiased manner. While many of the factors that influence model forecasts are beyond the control of modelers, there are some improvements that can be made to improve the model's predictive ability. For example, modelers typically use model validation techniques to evaluate a model's forecasting ability by comparing the model predictions with observed data, not used in model estimation (Zhao and Kockelman, 2002). While this technique assesses the model's ability to reproduce base year conditions, it does not ensure acceptable model performance for future predictions. Future model forecasts are subject to input and other inherent uncertainties and these factors change over time. The current model validation techniques do not capture these dynamic conditions. Use of techniques such as "backcasting", where modelers work backwards from some idea of a desirable future, could be used to improve model's performance. Moreover, a shift in thinking from using absolute numbers in to using ranges would diffuse criticisms against modeling. Acknowledgement of the inherent uncertainties in the modeling process coupled with a sensitivity analysis using ranges to show the variation in traffic forecasts with changes in the various inputs would certainly help the forecasting and decision making process. 
Table A2

Lookup Table to be used along with Figs. 3 and 4 .

\begin{tabular}{|c|c|c|c|c|c|}
\hline Id & Report & Id & Report & Id & Report \\
\hline 1 & SPAR-202 & 37 & TA-M296A & 73 & TAU 3451B \\
\hline 2 & TA-M372B & 38 & TA-M299 & 74 & SPARS 2 \\
\hline 3 & TA-M329 & 39 & TA-M304 & 75 & SPARS 2A \\
\hline 4 & TA-M335 & 40 & TA-M301 & 76 & SPARS 3 \\
\hline 5 & TA-M336 & 41 & TAS 3065A-14 & 77 & SPARS 4 \\
\hline 6 & TA-M337 & 42 & TAS 3074B & 78 & SPARS 15 \\
\hline 7 & TA-M343 & 43 & TAS $3074 \mathrm{C}-14$ & 79 & SPARS 16 \\
\hline 8 & TA-M238 & 44 & TAS 3080 & 80 & SPARS 17 \\
\hline 9 & TA-M240 & 45 & TAS 3081 & 81 & SPARS 18 \\
\hline 10 & TA-M242 & 46 & TAS 3081A-14 & 82 & SPARS 19 \\
\hline 11 & TA-M245 & 47 & TAU 3061A & 83 & SPARS 32 \\
\hline 12 & SPAR-208 & 48 & TA-М300 & 84 & SPARS 33 \\
\hline 13 & SPAR-208A & 49 & TAS 3066A-14 & 85 & SPARS 37 \\
\hline 14 & SPAR-210 & 50 & TA-M292 & 86 & SPARS 45 \\
\hline 15 & SPAR-220 & 51 & TAU 3065 & 87 & SPARS 48 \\
\hline 16 & SPAR-224 & 52 & TAU 3066 & 88 & SPARS 49 \\
\hline 17 & SPAR-227 & 53 & TAU 3069 & 89 & SPARS 53 \\
\hline 18 & SPAR-246 & 54 & TAU 3070 & 90 & SPARS 60 \\
\hline 19 & TA-M255A & 55 & TAU 3073 & 91 & SPARS 61 \\
\hline 20 & TA-M286 & 56 & TAU 3073A & 92 & SPARS 65 \\
\hline 21 & SPAR-215 & 57 & TAU 3074 & 93 & SPARS 69 \\
\hline 22 & SPAR-202A & 58 & TAU 3074A & 94 & SPARS 72 \\
\hline 23 & TA-M345 & 59 & TAU 3075 & 95 & SPARS 73 \\
\hline 24 & TA-M346 & 60 & TAU 3076 & 96 & SPARS 75 \\
\hline 25 & TA-M307 & 61 & TAU 3077 & 97 & SPARS 75A \\
\hline 26 & TA-M253 & 62 & TAU 3078 & 98 & SPARS 77 \\
\hline 27 & TA-M253 distributor addendum & 63 & PSU3203A & 99 & SPARS 78 \\
\hline 28 & TA-M302 & 64 & PSU3203B & 100 & TAS3562C \\
\hline 29 & TA-M207A & 65 & TAS3081B-14 & 101 & TAS3562D \\
\hline 30 & TA-M289A & 66 & TAS3082-14 & 102 & FEIS New U.S. Hwy 10 \\
\hline 31 & TA-M309 & 67 & TAS3084-14 & 103 & FEIS TH 3 \\
\hline 32 & TA-M311 & 68 & TAS3085-14 & 104 & FEIS TH 77/I-494 \\
\hline 33 & TA-M326 & 69 & TAU3204A & 105 & FEIS I35E \\
\hline 34 & TA-M358 & 70 & TAU 3205 & 106 & DEIS TH 610/TH 252 \\
\hline 35 & TA-M298 & 71 & TAU 3223 & 107 & FEIS US-12/I-394 \\
\hline 36 & TA-M308 & 72 & TAU 3451A & 108 & 20 -Year plan for district 9 \\
\hline
\end{tabular}

\section{Acknowledgements}

The authors would first like to acknowledge the efforts of Michael Iacono, University of Minnesota, for conducting the initial groundwork necessary for this study. The authors would like to thank the following individuals for their invaluable assistance through the study: Gene Hicks, Mn/DOT; Tom Nelson, Mn/DOT; Mark Levenson, Mn/DOT; Bob Paddock, Metropolitan Council; Steve Wilson, SRF Consulting Group, Inc; and Steve Ruegg, Parsons Brinckerhoff. The authors would also like to thank Charles Rodgers, Minnesota Historical Society, for allowing a temporary return of the transportation records archived at the Minnesota State Archive to help with the data collection efforts. The authors would like to thank Allen Mattson and John Cook at the Facilities Management Office at the University of Minnesota for allowing the use of large format scanners and for their assistance in the scanning process. The authors also appreciate the guidance provided by Mark Filipi, Metropolitan Council; Steve Alderson, Mn/DOT (ret.); Brian Vollum, Mn/DOT (ret.); George Cepress, Mn/ DOT (ret.); and other members of the Technical Advisory Panel (TAP). Finally the authors would like to thank Josh Potter and Anthony Jakubiak for their invaluable assistance with the data collection efforts without which this work would not have been possible.

\section{Appendix A}

Summary of project reports in the database is given in Table A1. A lookup table of the project identifier with the actual report number, used in Figs. 3 and 4 is provided in Table A2 in the Appendix.

\section{References}

Altshuler, A.A., Luberoff, D., 2003. Mega-Projects: The Changing Politics of Urban Public Investment. Brookings Institution Press; Lincoln Institute of Land Policy, Washington, DC, Cambridge, MA.

Ashley, D., 1980. Uncertainty in the context of highway appraisal. Transportation Research 9, 249-267.

Bain, R., Polakovic, L., 2005. Traffic forecasting risk study update 2005: through ramp-up and beyond. Standard \& Poors, London.

Chang, K.-T., Khatib, Z., Ou, Y., 2002. Effects of zoning structure and network detail on traffic demand modeling. Environment and Planning B 29, 37-52.

Clarke, M., Dix, M., Jones, P., 1981. Eror and uncertainty in travel surveys. Transportation 10, 105-125.

Daly, A.J., Ortuzar, J., 1990. Forecasting and data aggregation: theory and practice. Traffic Engineering \& Control 31, 632-643.

de Jong, G., Daly, A., Pieters, M., Miller, S., Plasmeijer, R., Hofman, F., 2007. Uncertainty in traffic forecasts: literature review and new results for The Netherlands. Transportation 34, 375-395.

Flyvbjerg, B., 2005. Measuring inaccuracy in travel demand forecasting: methodological considerations regarding ramp up and sampling. Transportation Research Part A 39, 522-530.

Flyvbjerg, B., Bruzelius, N., Rothengatter, W., 2003. Megaprojects and Risk: An Anatomy of Ambition. Cambridge University Press, United Kingdom.

Flyvbjerg, B., Holm, M., Buhl, S., 2005. How (in) accurate are demand forecasts in public works projects? Journal of the American Planning Association 71 131-146.

Flyvbjerg, B., Holm, M., Buhl, S., 2006. Inaccuracy in traffic forecasts. Transport Reviews 26, 1-24.

Gendell, M., 2008. Older workers: increasing their labor force participation and hours of work. Monthly Laboratory Review 131, 41.

Gilbert, D., Jessop, A., 1977. Error and uncertainty in transport models. In: Transportation Models: Proceedings of Seminar G, PTRC Summer Annual Meeting, University of Warwick, United Kingdom, June 1977. 
Goodwin, P., 1996. Empirical evidence on induced traffic. Transportation 23, 35-54.

Horowitz, J., Emslie, R., 1978. Comparison of measured and actual traffic volumes on urban interstate highways. Transportation Research 12, 29-32.

Hugosson, M., 2005. Quantifying uncertainties in a national forecasting model. Transportation Research Part A 39A, 531-547.

Johnston, R., Ceerla, R., 1996. Travel modeling with and without feedback to trip distribution. Journal of Transportation Engineering 122, 83-86.

Kain, J., 1990. Deception in dallas: strategic misrepresentation in rail transit promotion and evaluation. Journal of the American Planning Association 56, 184-196.

Land Management Information Center, 2008. 'Datanet'. Accessed May 2008 URL:〈http://www.Imic.state.mn.us/datanetweb/php/census2000/c2000.html >.

Lewis-Workman, S., White, B., McVey, S., Spielberg, F., 2007. The Predicted and Actual Impacts of New Starts Projects-Capital Costs and Ridership. Federal Transit Administration and Vanasse Hangen Brustlin, Inc, Washington, DC.

Mackinder, I.H., Evans, S.E., 1981. The predictive accuracy of British transport studies in urban areas. Transport and Road Research Laboratory, Crowthorne, Berkshire, United Kingdom.

Mahmassani, H., 1984. Uncertainty in transportation systems evaluation: issues and approaches. Transportation Planning and Technology 9, 1-12.

Metropolitan Council of the Twin Cities Area, 2003. 2000 Travel Behavior Inventory home interview survey: data and methodology. Metropolitan Council, St. Paul, MN.

Metropolitan Council of the Twin Cities Area, 2004. 2030 Transportation Policy Plan. Metropolitan Council, St. Paul, MN.

Minnesota Population Center, 2008. National Historical Geographic Information System. URL: $\langle$ http://www.nhgis.org/ $>$ accessed May 2008.
Niles, J., Nelson, D., 2001. Identifying uncertainties in forecasts of travel demand URL: 〈http://www.globaltelematics.com/NilesNelson2001.pdf $\rangle$ accessed October 2007.

Noland, R., 2001. Relationships between highway capacity and induced vehicle travel. Transportation Research Part A 35, 47-72.

Noland, R., Lem, L., 2000. Induced travel: a review of recent literature and the implications for transportation and environmental policy. Appraisal of Road Transport Initiatives: Proceedings of Seminar D, European Transport Conference, Cambridge, United Kingdom.

Page, J., Levenson, M., Stewart, B., 1981. Twin Cities Forecasting Accuracy Study. Minnesota Department of Transportation, St. Paul, MN.

Pell, C., Meyburg, A., 1985. Sources of error and their implications for uncertainty in urban transportation planning forecasts. In: 64th Annual Meeting of the Transportation Research Board, Washington, DC.

Pickrell, D., 1992. A desire named streetcar: fantasy and fact in rail transit planning. Journal of the American Planning Association 58, 158-176.

Richmond, J., 2001. A whole-system approach to evaluating urban transit investments. Transport Reviews 21, 141-179.

Robinson, J., 1988. Unlearning and backcasting: rethinking some of the questions we ask about the future. Technological Forecasting and Social Change 33, 325-338.

Rodier, C., 2004. Verifying accuracy of regional models used in transportation and air quality planning: case study in Sacramento, California, Region. Transportation Research Record 1898, 45-51.

Talvitie, A., Dehghani, Y., Anderson, M., 1982. An investigation of prediction errors in work trip mode choice models. Transportation Research A 16, 395-402.

Wachs, M., 1992. Ethical dilemmas in forecasting for public policy. Public Administration Review 42 (6), 562-567.

Zhao, Y., Kockelman, K., 2002. The propagation of uncertainty through travel demand models: an exploratory analysis. The Annals of Regional Science 36 145-163. 